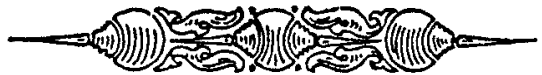

\title{
FEMALE RECEPTIVITY, EMBRYONIC DIAPAUSE, AND SUPERFETATION IN THE EUROPEAN BADGER (MELES MELES): IMPLICATIONS FOR THE REPRODUCTIVE TACTICS OF MALES AND FEMALES
}

\author{
Nobuyuki Yamaguchi \\ Wildife Conservation Research Unit, University of Oxford \\ Tubney House, Abingdon Road, Tubney, Abingdon OX13 5QL United Kingdom \\ E-MAIL: NOBUYUKI.YAMAGUCHI@ZOO.OX.AC.UK
}

Hannah L. Dugdale

Wildlife Conservation Research Unit, University of Oxford

Tubney House, Abingdon Road, Tubney, Abingdon OX13 5QL United Kingdom

E-MAIL: HANNAH.DUGDALE@ZOO.OX.AC.UK

David W. Macdonald

Wildlife Conservation Research Unit, University of Oxford

Tubney House, Abingdon Road, Tubney, Abingdon OX13 5QL United Kingdom

E-MAIL: DAVID.MACDONALD@ZOO.OX.AC.UK

KEYWORDS

blastocyst, delayed implantation, mate guarding, progesterone, superfecundation

ABSTRACT

The European badger Meles meles is thought to mate throughout the year, with two mating peaks occurring in late winter/spring and summer/autumn. After mating, fertilized ova enter embryonic diapause (delayed implantation) at the blastocyst stage, which lasts up to eleven months. Even if mating is successful, however, the estrous cycle may continue during embryonic diapause, which suggests that female badgers are capable of superfetation (conception during pregnancy). This may increase female fitness by facilitating polyandry, and reduce the risk of infanticide by resident males through paternity confusion. Detailed understanding of female receptivity, specifically the association of superfetation with embryonic diapause, may explain field observations of seemingly inconsistent reproductive

The Quarterly Review of Biology, March 2006, Vol. 81, No. 1

Copyright (C) 2006 by The University of Chicago. All rights reserved.

0033-5770/2006/8101-0002\$15.00 
tactics of male badgers with regard to, for instance, whether or not they guard mates or defend territories. The combination of embryonic diapause and superfetation may occur in other mustelids; if so, the sociobiology of mustelids will need re-evaluating, and the Mustelidae may prove to be a good model taxon for studies of sexual conflict in the reproduction of eutherian mammals.

$\mathrm{N}$ ATURAL SELECTION and sexual selection act on both sexes. However, emphasis on sexual selection as a directional evolutionary force acting on males has diverted attention from the selective processes acting on females, whose discrete mating tactics may have masked the extent of the potential for reproductive conflict between the sexes (Zeh and Zeh 2003). Recent evidence suggests that the reproductive interests of males and females frequently differ, thereby generating sexual conflict rather than cooperation (Chapman et al. 2003; Montrose et al. 2004). This is highlighted in polyandrous mating systems, which may be the norm across various taxa (Chapman et al. 2003; Zeh and Zeh 2003). Such sexual conflict is manifested as a "tug-of-war" at both precopulatory and postcopulatory stages, with males attempting to monopolize access to the females' ova and manipulate their physiology, while females attempt to control their own reproductive options (Chapman et al. 2003; Zeh and Zeh 2003; Hosken and Stockley 2004; Martin et al. 2004). Therefore, it is important to understand the mechanisms through which males and females achieve reproductive success (Zeh and Zeh 2003).

Understanding sociobiology requires knowledge of the tactics that maximize individual survival and reproductive success, which are determined by the availability of food and shelter for both sexes and the receptivity of females for males (Macdonald 1983; Sandell 1989). In spite of the theoretically accepted importance of the pattern of female receptivity, empirical information, particularly on reproductive physiology and endocrinology, is rudimentary for many species. Furthermore, it has recently been suggested that the unusual reproductive phenomenon of superfetation (conception during pregnancy; Shackelford 1952) that occurs in female American mink Mustela vison may, in combination with embryonic diapause (delayed implantation of embryos), play a crucial role in sexual con- flict in American mink reproduction, and this phenomenon may occur in other members of the Mustelidae (Thom et al. 2004b; Yamaguchi et al. 2004). The Mustelidae is unusual amongst eutherian families (placental mammals), as not only is it comprised of approximately one-third of the species known to exhibit embryonic diapause (Mead 1981; Sandell 1990; Ben-David 1998; Renfree and Shaw 2000; Thom et al. 2004a), but also all additional transitions of the evolution of embryonic diapause amongst the Carnivora occur within the Mustelidae (Lindenfors et al. 2003). The possible connections between embryonic diapause and superfetation, and their importance with regards to sexual conflict in the Mustelidae, merit consideration. The aim of this paper is to shed light on the importance of female reproductive physiology for the evolution of reproductive tactics of both sexes by focusing on another mustelid, the European badger Meles meles, for which relatively robust information is available in terms of its ecology, behavior, and reproductive physiology.

\section{Distribution and Social Organization}

The European badger (Meles meles) is a large, stocky mustelid that weighs around 10 $\mathrm{kg}$. It is widely distributed across Eurasia, from the U.K. to Japan and from Palestine to the Russian Arctic Circle. It exhibits large variation in social organization, being solitarily, pair, or small group living in many parts of Eurasia and group living in parts of the U.K. This is unique among badgers as all others are solitary (e.g., the American badger Taxidea taxus; Macdonald 2001). Social groups of badgers can be composed of up to 30 individuals that share a large communal "sett" or den (a network of underground tunnels and chambers; Neal and Cheeseman 1996; Johnson et al. 2002). However, cooperative behaviors amongst group members are less developed than those seen in highly social mammalian species such as wolves Canis lupus 
(da Silva et al. 1994; Woodroffe and Macdonald 2000; Macdonald et al. 2002b; Revilla and Palomares 2002; Rogers et al. 2003). Currently a considerable bias exists in the literature on Meles meles because a disproportionate number of studies have been conducted in the U.K. where these badgers live in social groups. The reported reproductive biology thus may not be applicable throughout its range (Neal and Cheeseman 1996; Johnson et al. 2002). The identity of the population from which data were derived is therefore specified throughout this paper.

\section{MATing AND Birth}

Since the classic work of Neal and Harrison (1958), based on about 85 animals from southern England, post mortem studies of the reproductive biology of free-ranging badgers include: Canivenc and Bonnin-Laffargue (1963: about 600 from France), Canivenc (1966: about 700 from France), Ahnlund (1980: 1095 from central Sweden), Wandeler and Graf (1982: 230 from Switzerland), Cresswell et al. (1992: 650 from southern England, U.K.), Whelan and Hayden (1993: 548 from central Republic of Ireland), and Page et al. (1994: 1875 from southern England).

Badgers can mate during any month in Britain (Neal and Cheeseman 1996). Seasonal changes in the wet weight of testes combined with epididymides, and the presence or absence of spermatozoa in the caput epididymis, of males suggest that testicular activity in southern England is, on average, highest during late winter to summer and lowest during late autumn to early winter (Figure 1) (Neal and Harrison 1958; Page et al. 1994; Neal and Cheeseman 1996). There are always some males that are physiologically capable of reproduction at any time of the year, however, and this capability has been confirmed in vivo in Wytham Woods, Oxford, southern England (Woodroffe and Macdonald 1995b). Although many matings last less than two minutes, some last more than 15 minutes (up to 90 minutes; Johnson 2001), and these are speculated to represent successful matings (Neal and Harrison 1958; Neal and Cheeseman 1996). Although the existence of such

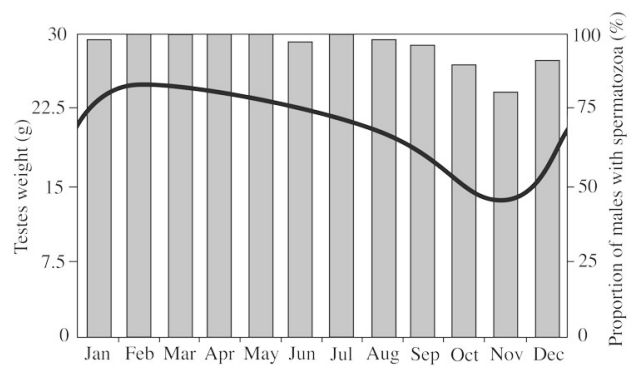

Figure 1. Seasonal Variation in Testes Weight AND the Proportion of Males with SPERMATOZOA

The generally high levels of testicular activity as shown by testes weight (bar chart) and the proportion of animals with spermatozoa (solid line) among adult males in their third year or older. Testes weight is the average wet weight of testes combined with epididymides, both with and without spermatozoa.

long-duration matings may suggest that stimulation associated with intromission is important in badger reproduction, whether or not the badger is an induced ovulator remains unconfirmed. It has been suggested that ovulation could occur without copulatory stimulation, and that spontaneous ovulation might occur in the American mink, a related species and an induced ovulator whose reproductive biology has been well studied in captivity (Sundqvist et al. 1988). Therefore, these two forms of ovulation may not be mutually exclusive and further studies are necessary to establish whether or not badgers are induced ovulators.

Observations of long-duration matings, both in the field and in captivity, are most frequent between February and May in Britain (Neal and Cheeseman 1996; Johnson 2001), which suggests this is an important period in the reproduction of British badgers. Cresswell et al. (1992) demonstrated that in southern England, U.K., the proportion of females carrying large $(>1.0 \mathrm{~mm}$ diameter $)$ pre-ovulatory follicles peaks twice a year: one peak occurs in late winter to spring and another in summer to autumn (Figure 2), suggesting that badgers in that region have two peaks of reproductive activity. However, as one may speculate from Figure 2, it is possible that throughout most of the year some females are always physiologically receptive to 


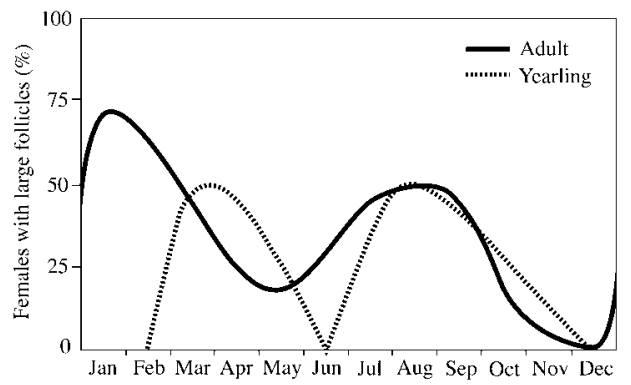

Figure 2. Seasonal Occurrence of Large ( $>1.0$ ma) Follicles in Female Badgers

The general occurrence of large follicles in female badgers in both their third year or older (adult) and in their second year (yearling) throughout the year, showing two peaks of reproductive activity.

mating. Nevertheless, the majority of females are pregnant by early summer (April to June) in southern England, as well as in central Sweden and in Switzerland (Figure 3) (Ahnlund 1980; Wandeler and Graf 1982; Cresswell et al. 1992; Whelan and Hayden 1993; Page et al. 1994). Unfortunately, conducting yearround behavioral observations of badgers is very difficult even at the setts because they are a nocturnal species that spend much of their time underground. Badgers are not individually identifiable on the basis of their natural markings, and consequently, there is no published behavioral information on the frequency of matings throughout the year by identified individuals. The application of appropriate observation methods, such as infrared video surveillance to record badger activities at the setts with each individual identified by fur clip marks (Stewart and Macdonald 1997; Stewart et al. 1997), should be encouraged widely to collect such data.

Due to well-synchronized implantation dates facilitated by embryonic diapause, regardless of the timing of successful matings, the great majority of births occur within a short period during late winter-spring (Neal and Cheeseman 1996). This holds true throughout the badger's range, although the timing of the peak may vary from one geographical region to another in terms of the calendar month (Neal and Cheeseman 1996). In contrast to the potential for yearround mating activity, in southern England,

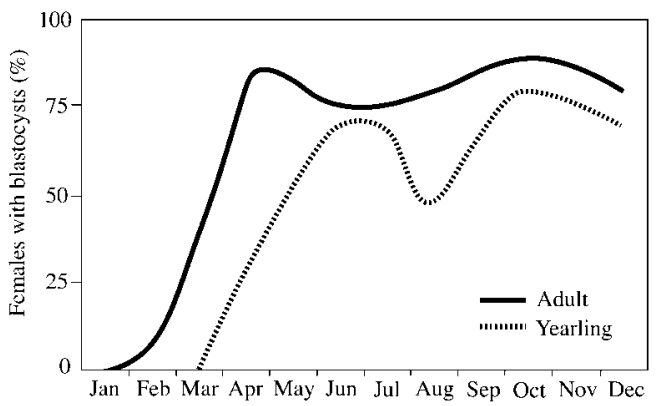

Figure 3. Seasonal Occurrence of Blastocysts in Female Badgers

The general trend in the occurrence of blastocysts in female badgers throughout the year. The majority of females both in their third year or older (adult) and in their second year (yearling) are pregnant by May.

the most accurately estimated birth dates ( $76 \%$ of the 97 litters examined) fall between mid-January and mid-March, with a peak during the first fortnight in February (Neal and Cheeseman 1996). The modal number of cubs at birth is estimated to be three, and the estimated mean is 2.8 with a range of one to five (Neal and Cheeseman 1996). By the time cubs are seen above ground at eight to ten weeks after birth, the average number in a litter is reduced to 2.4. In Wytham Woods, Oxford, mean fetal litter size is 1.8 (Woodroffe and Macdonald 1995b) and postemergence litter size is 1.6 (Macdonald and Newman 2002). There is speculation that this decrease may be due to infanticide by other breeding females in the sett (Cresswell et al. 1992), although in Wytham some result from coccidial infection (Newman et al. 2001).

\section{EMbryonic Diapause}

Reproductive delay can also be achieved through delayed fertilization and delayed development, but the most widespread means in mammals is embryonic diapause. During embryonic diapause, a newly fertilized egg (or eggs) temporarily ceases development and remains free in the uterus lumen instead of being directly implanted into the uterus (Sandell 1990; Mead 1993; Bernard and Cumming 1997; Renfree and Shaw 2000; Lindenfors et al. 2003). Embryonic diapause has been found in 69 eutherian (including 3 spe- 
cies of Chiroptera, 4 Insectivora, 2 Edentata, 18 Rodentia, 41 Carnivora, and 1 Artiodactyla) and 28 marsupial species among about 4,600 mammalian species (Mead 1993; Renfree and Shaw 2000). Two different forms of embryonic diapause are distinguished. Obligate (or seasonal) diapause usually occurs in species that have a single litter per year, and it is controlled by extrinsic factors such as day length. Facultative (or lactational) diapause is usually associated with multiple litters per year, and it is controlled by intrinsic factors such as the duration of lactation of the previous litter (Sandell 1990; Mead 1993; Renfree and Shaw 2000).

In the European badger, ovulation and fertilization can occur a few days after parturition, in late winter-early spring (January to March); implantation does not occur until mid-winter (December to January), however (Canivenc and Bonnin 1981; Woodroffe 1995; Dugdale et al. 2003). Therefore, due to this embryonic diapause, which is known to occur in 22 (and is considered not to occur in 11) of the 55 species of the family Mustelidae (Mead 1981; Sandell 1990; Ben-David 1998; Amstislavsky and Ternovskaya 2000; Lindenfors et al. 2003; Thom et al. 2004a), the badger's gestation period, which includes the reported 40 to 49 days postimplantation (Canivenc 1966; Neal and Cheeseman 1996), is hugely inflated to almost 11 months (Canivenc and Bonnin 1981; Mead 1981; Sandell 1990; Ben-David 1998). The existence of unimplanted blastocysts in the badger was first reported by Fries (1880). Later Fischer (1931) showed that embryonic diapause occurs in the badger. Endocrinologically, it is thought that embryonic diapause in mustelids results from insufficient hormonal secretion from the pituitary gland, including prolactin and LH (luteinizing hormone), which causes incomplete differentiation of the corpora lutea and reduced luteal hormonal secretion (Canivenc and Bonnin 1981; Sundqvist et al. 1988; Mead 1993; Renfree and Shaw 2000). In the badger, corpora lutea are formed after ovulation, but they are considerably smaller than those seen during the postimplantation pregnancy, and appear less active during embryonic diapause (Canivenc and Bonnin 1981; Wandeler and Graf 1982).
Renewed luteal development is associated with a change in photoperiod and increased pituitary secretion, triggering resumption of luteal cell differentiation and increased secretion of luteal hormones, including progesterone. This in turn is probably responsible, through uterine development and secretion, for the resumption of embryonic development and implantation (Canivenc 1966; Sundqvist et al. 1988; Mead 1993; Renfree and Shaw 2000). As summarized in Figure 4, progesterone levels, although still low, are significantly elevated when embryogenesis is renewed, which suggests progesterone-dependent implantation; however, attempts have failed to stimulate implantation artificially by administering progesterone (Canivenc 1966; Canivenc and Bonnin 1981).

During embryonic diapause, embryogenesis is retarded at the blastocyst stage (where the hollow ball of embryo cells has developed into two layers of cells), and further development does not occur until the embryos are implanted in the uterus. However, it is incorrect to consider that blastocysts are in complete suspended animation during diapause (Mead, 1993; Renfree and Shaw, 2000). In carnivores, blastocysts are not totally metabolically inactive during embryonic diapause as oxygen consumption is continuous, and the synthesis of RNA, DNA, and protein continues, although at reduced rates compared to activated blastocysts (Mead 1993; Renfree and Shaw 2000). Additionally, unimplanted blastocysts undergo a gradual increase in diameter due to fluid accumulation within the blastocoele and increased cell numbers in the trophoblast (the outermost cell layer in the blastocyst) (Neal and Harrison 1958; Mead 1993; Renfree and Shaw 2000). This gradual increase in the size of unimplanted blastocysts is thought to be useful for investigating the time of year at which ovulation and fertilization occurred. Cresswell et al.'s (1992) report of seasonal changes in the size of unimplanted blastocysts (diameter range: about $0.1-0.2 \mathrm{~mm}$ in February, about $1.2-2.8 \mathrm{~mm}$ for the "first cohort" and about $0.2-0.7 \mathrm{~mm}$ for the "second cohort" in September, and about $2.5-4.0 \mathrm{~mm}$ for the "first cohort" and about 1.4-1.8 $\mathrm{mm}$ for the "second cohort" in December) in female badgers in southern 


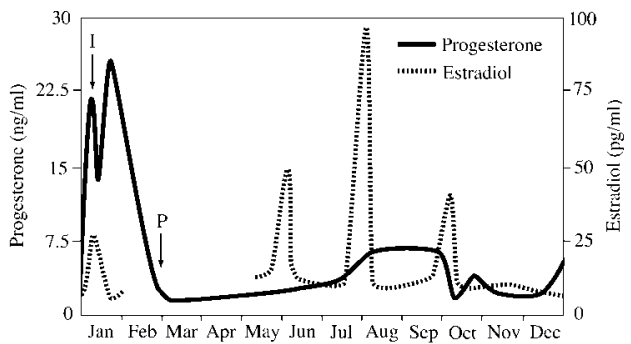

Figure 4. Seasonal Variation in Plasma Progesterone and Estradiol Profiles Elevated progesterone levels, although low, at embryogenesis renewal, which suggests progesterone-dependent implantation. Captive female badgers were housed separately and were not introduced to males during the monitoring period. Parturition is indicated with an arrow labeled "P" and estimated time of implantation is indicated by an arrow labeled "I."

England suggests the existence of two distinguishable peaks of ovulation and fertilization corresponding with the occurrence of large follicles (Figures 2 and 5). When the oviducts of badgers were severed in March, however, blastocysts recovered at autopsy were of unequal size, although they were thought to belong to the same ovulation (Canivenc 1966). Although Canivenc (1966) did not give further details (e.g., how large the size discrepancy was and proof that all of the blastocysts belonged to the same ovulation), these are grounds for caution when timing ovulation(s) solely from the size of blastocysts. This is further reinforced by the observed variation (ranging 0.6-1.1 $\mathrm{mm}$ in diameter) in the size of unimplanted blastocysts apparently from the same ovulation observed in western spotted skunk Spilogale putorius latiforms (Rodney Mead personal communication).

\section{Loss OF BLASTOCySTS AND SuPERFETATION}

Throughout embryonic diapause, the average number of blastocysts per female is fairly constant (Figure 6; Creswell et al. 1992; Page et al. 1994). However, the average number of corpora lutea increases during the same period (Figure 6) (Neal and Harrison 1958; Ahnlund 1980; Page et al. 1994). Furthermore, direct comparison between these two figures, based on the same females, shows

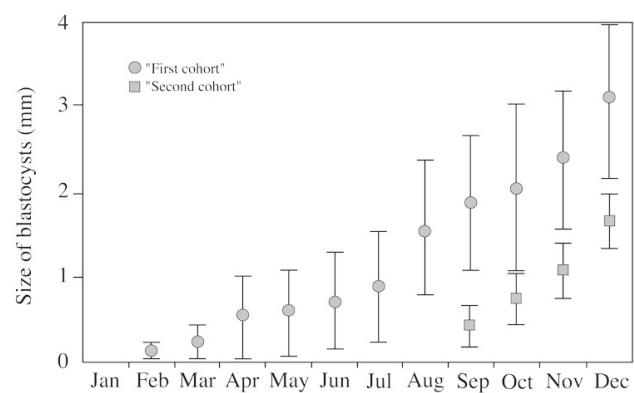

Figure 5. Seasonal Variation in the Diameter OF UNimplanted Blastocysts

The seasonal changes in the median and the range of the diameter of unimplanted blastocysts. There appears to always be a distinct gap between the size ranges of the larger "first cohort" and the smaller "second cohort" blastocysts, the later of which occur from September onwards.

that in general there are more corpora lutea than blastocysts, as highlighted in extreme cases where more than ten corpora lutea, but no blastocysts, were observed (Neal and Harrison 1958; Ahnlund 1980; Page et al. 1994). However, small blastocysts, formed just before examination, may have been missed during dissection, which may account for the large difference observed between the number of corpora lutea and blastocysts in March (Figure 6). The difference in the number of corpora lutea and blastocysts throughout the mating season tentatively suggests that more ova are ovulated than are retained as blastocysts (Ahnlund 1980; Wandeler and Graf 1982; Cresswell et al. 1992; Page et al. 1994). Additionally, there are females that possess blastocysts that visibly differ in size, which has been interpreted as an indication of superfetation (Neal and Harrison 1958; Cresswell et al. 1992; Neal and Cheeseman 1996), but the possibility that these blastocysts of different sizes belong to the same ovulation (Canivenc 1966) cannot be dismissed. Furthermore, in addition to normal follicular development leading to corpora lutea vera (corpora lutea that are formed following ovulations primarily by the proliferation and hypertrophy of the membrane granulosa), atresia can also occur and lead to the production of corpora lutea atretica (corpora lutea that are primarily formed without ovulations from 


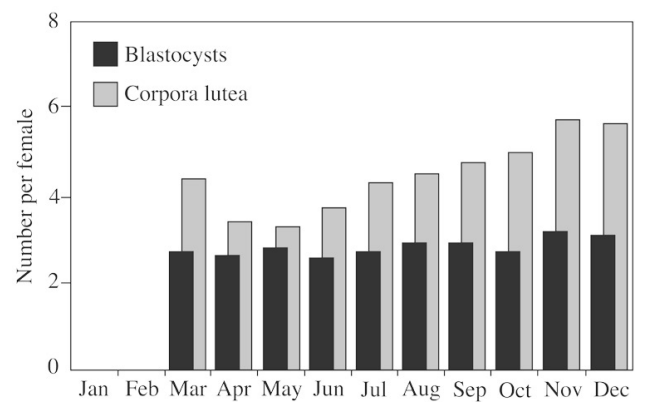

Figure 6. Seasonal Variation in the Average Number of Blastocysts and Corpora LUTEA

The seasonal changes in the numbers of blastocysts and corpora lutea among adult females in their third year or older. The number of blastocysts tends to remain relatively constant while the numbers of corpora lutea tend to increase towards the end of the breeding season.

undifferentiated stromal and thecal cells) (Mead 1968). These are very difficult to distinguish between, and can also be mistaken with corpora lutea accessorium (formed by the lutenization of the granulose cells of unovulated follicles) (Mead 1968). This should be considered when interpreting the difference in the observed number of corpora lutea and blastocysts (Wandeler and Graf 1982; Rodney Mead personal communication). The foregoing arguments suggest that, although superfetation is thought to occur in the European badger (Neal and Harrison 1958; Cresswell et al. 1992; Neal and Cheeseman 1996), definitive evidence is still required.

Superfetation has been well studied in the American mink. In ranched mink, ova from a single ovulation can be fertilized by more than one male when other males mate within one to three days of the initial mating, a phenomenon known as superfecundation (Shackelford 1952; Venge 1973). Furthermore, female American mink continue to ovulate after the initial fertilization if more than six days elapse between matings; thus, kits can be sired by more than two males that fertilize the ova of different ovulations: superfetation (Shackelford 1952; Mead 1994). Superfetation is a phenomenon where ovulation and fertilization (and usually implantation) of the second (and subsequent) set(s) of ova occurs during pregnancy whether or not the subsequent parturition is successful. Superfetation has been reported in humans (Steck and Bussen 1997) and in some domestic animals (ewe: Schuyt 1981; pig: Hall 1987; cow: Rottenstein 1989), however, these are rare cases that have usually occurred under medical/ veterinary pregnancy treatments. Confirmed reports of natural superfetation during normal reproduction of a species resulting in successful parturition are extremely rare in eutherian mammals. Apart from the American mink, and possibly the European badger, superfetation has only been reported in the casiragua Proechimys semispinosus (Weir 1974), the North African gundi Ctenodactyles gundi (Gouat 1985), the brown hare Lepus europaeus (Caillol et al. 1991), and possibly the common tenrec Tenrec ecaudatus (Poduschka 1996). However, superfetation in these four species, which occurs without embryonic diapause, is characterized by a second estrus just before parturition of the fetuses that developed from the first set of ova. Therefore, although the second ovulation occurs before parturition, each set of ova develop separately in essentially two different pregnancies leading to two different parturitions, in a fundamentally different process from that occurring in association with embryonic diapause. This means that among eutherian mammals, there are only two species where biologists currently know or presume that both embryonic diapause and superfetation occur, the American mink and the European badger. This is due to a lack of evidence of superfetation rather than proof that superfetation does not occur in other species that possess embryonic diapause.

We present four hypotheses to explain the difference in the number of blastocysts and corpora lutea. The first hypothesis assumes that badgers are induced ovulators and that some of the blastocysts from early ovulations may be lost and replaced through superfetation during embryonic diapause. Detailed studies on the reproductive biology of female American mink also indicate that during embryonic diapause, a longer delay until implantation decreases the survival of fertilized ova (Shackelford 1952; Venge 1973). The extent 
to which this occurs in badgers is unknown. Studies in a few species of the genus Martes suggest, on the basis of the similar numbers of corpora lutea and unimplanted embryos, that there is little evidence for preimplantation loss of embryos (Mead 1994). Based on these studies, it may be speculated that most embryo loss occurs during postimplantation in many mustelids that delay implantation, and the American mink is an exception (Rodney Mead personal communication). A presumed preimplantation loss of blastocysts is reported in the European badger (Creswell et al. 1992), strongly suggesting that further detailed studies are necessary to obtain a better understanding of the possible blastocyst turnover during the embryonic diapause and superfetation. The only published study to investigate atrophying blastocysts used live animals and found that marked blastocysts from postpartum ovulations were all present and implanted in January (Canivenc and BonninLaffargue 1963). However, ultrasound of female badgers in Wytham Woods, Oxford revealed that a female in January 2003 had one vesicle that was being reabsorbed, and a female in January 2004 had one embryo in the right uterine horn and a vesicle in the same horn that was being reabsorbed (Dugdale unpublished data). Although at an advanced stage in development, this suggests that atrophy of blastocysts may also occur. This first hypothesis explains the fairly constant number of blastocysts per female throughout embryonic diapause in spite of the increase in the number of corpora lutea.

The second hypothesis is that if spontaneous ovulation occurs in badgers, the surplus corpora lutea could come from ova that are not fertilized, and hence not retained. In American mink (an induced ovulator), it is suggested that intromission may not always be necessary for ovulation and that rough fighting associated with courtship foreplay may lead to ovulation (Dunstone 1993). This suggests a third hypothesis that the surplus corpora lutea are the result of induced ovulation(s) where ovulated ova are not subsequently fertilized. The presence of degenerate and apparently unfertilized ova along with healthy blastocysts (Harrison and Neal 1956) accords with either (or both) of the latter two hypotheses.

The fourth hypothesis is that the surplus corpora lutea are due to the three types of corpora lutea, mentioned above, being incorrectly classified together as indications of ovulations. Neal and Cheeseman (1996) appear to consider that the first hypothesis is the most likely. It seems possible that female European badgers ovulate more than once within a single breeding season, which lasts for nearly a year, regardless of whether or not ovulation and fertilization occur in the early stage of that breeding season.

In ranched American mink, more than four waves of follicles mature at approximately eight day intervals during the mating season (Sundqvist et al. 1988), although the maximum number of times a female can ovulate after successful matings is unknown. It is not known how many times a female badger ovulates during one breeding season. Service et al. (2002) suggest, based on the estradiol concentration of urine samples from two unmated females monitored daily for a year, that up to five estrous cycles may occur in late winter/spring and autumn with an average interval of 28 days. Plasma estradiol levels in freeranging female badgers from southwest France show three recognizable peaks during embryonic diapause in June, August, and October. These peaks correspond extremely well with the seasonal changes in plasma estradiol levels, monitored on average once a week, in five captive females from the same region (Figure 4) (Mondain-Monval et al. 1980). The observed peaks in plasma estradiol (along with another estrogen: estrone) may be linked to the keratinization and epithelial proliferation of vaginal mucosa, which occurs at the same time (Mondain-Monval et al. 1980). However, it is not clear if such estradiol peaks are associated with estrus, which is defined as the period of sexual receptivity, since the five observed females (Mondain-Monval et al. 1980) were housed separately and without any contact with males. Similarly, although spontaneous ovulation was not observed in any of the females during these estrus-like periods (Mondain-Monval et al. 1980), it does not necessarily follow that badgers do not ovulate after the postpartum mat- 
ing season, especially if induced ovulation is the main form of ovulation in badgers. At present, we do not know how many times a female badger (in captivity or various natural circumstances) can physiologically ovulate during the year-long breeding season and how long the interval is between these ovulations.

\section{IMPLICATIONS FOR THE REPRODUCTIVE Tactics of Males}

Territorial males are expected, theoretically, to expel intruders in order to maximize their own reproductive success (e.g., Maynard-Smith 1978). However, a lack of understanding of female receptivity seems to have thwarted a consistent explanation of seemingly contradictory reproductive tactics of male badgers.

Roper et al. (1993) monitored latrines intermittently throughout the year while radiotracking four males and two females in southern England. Whereas the spring peak (March and April) in scent-marking was attributable to both sexes, the autumn peak (September and October) was mainly attributable to males. They concluded that both sexes are territorially most active in spring, but that males also showed a minor secondary increase in territorial activity in autumn. Cresswell et al. (1992) reported that bite wounding in males, interpreted as indicative of increased intrasexual competition among males, followed a roughly bimodal pattern, with one distinct peak in February and March and a less defined peak around September, and that bite wounding of females has two peaks in April and between November and December, in the badger populations of southern England. On the other hand, Macdonald et al. (2004) found no seasonal bitewounding pattern in either sex in the Wytham Woods population. Macdonald et al. (2002a) reported that, in general, individual body mass, body condition, and fecundity decreased with increasing group size in their study population. Interestingly, female badgers exhibited the greatest effects of densitydependent constraints on body mass and condition in autumn, whereas for males the effect was most pronounced in spring (Mac- donald et al. 2002a). Additionally, whereas females showed no sex-related preferences when scent-marking other badgers within their social group, males preferred females (Buesching et al. 2003). These reported sexual and seasonal differences in latrine usage, bite-wounding patterns, body condition, and scent-marking patterns suggest that male and female specific reproductive tactics do exist. These are therefore grounds to expect behaviors such as mate-guarding and territory defense in male badgers (Roper et al. 1986; Roper et al. 1993; Christian 1995). Nevertheless, a general consensus has not been reached in terms of male reproductive tactics, although male-male aggression appears to occur.

Revilla and Palomares (1999) reported the expansion of a male badger's territory after the removal of a neighboring male, which suggests that the male was attempting to gain access to females in the adjacent territories. There is also a report of a resident male fighting and chasing away an outsider male that was attempting to mate in the resident male's territory in early February (Christian 1995). However, in general there is little evidence to support the occurrence of mate-guarding by males (Cresswell et al. 1992). Indeed, behavioral observations suggest that male-male aggression is rare (Macdonald et al. 2002b), and males are even seen grooming each other before mating with the same female (Johnson 2001). Furthermore, it is also suggested that territories may not be exclusive even during the peak breeding periods when males are known to make sorties into neighboring territories (Woodroffe 1993; Neal and Cheeseman 1996).

In general, male mammals associating with certain females either socially or spatially try to guard, or conceal, those females from other males (Brotherton and Manser 1997; Jennions 1997). However, female badgers may advertise their receptivity widely through scent marking (Stewart et al. 2001, 2002; Buesching et al. 2002), and are themselves easy to locate during the day at either the main or outlier (smaller setts within the territory) setts of their social group (Roper et al. 2001), although they may range widely at night. The general lack of cooperative behav- 
iors among group members (da Silva et al. 1994; Woodroffe and Macdonald 2000; Macdonald et al. 2002b; Revilla and Palomares 2002; Rogers et al. 2003) suggests that it is uncommon for resident males to act cooperatively to evict trespassing males; thus, a single male outsider may manage to mate in neighboring territories (Woodroffe 1993; da Silva et al. 1994; Woodroffe et al. 1995). Indeed, on the rare occasions that a mating male was observed to chase away another male, a third male then mated with the female (Johnson 2001). However, mating success will depend upon female receptivity.

In the American mink, the earlier fertilization occurs in the breeding season, the longer the delay until implantation, which decreases the survival of fertilized ova (Shackelford 1952; Venge 1973). Hence, the later a male mates, the greater the proportion of the litter he is likely to sire (Shackelford 1952; Venge 1973). When female American mink mate again within 7 to 28 days of the first mating, less than $10 \%$ of kits are sired by the first male (Shackelford 1952; Mead 1994). In badgers, it is not known if males mating later have better chances of siring a larger proportion of the litter. Based on the size of unimplanted blastocysts in females sampled between September and December, Cresswell et al. (1992) show that about $65 \%$ and $35 \%$ of all blastocysts are from winter/spring and summer/autumn matings respectively. As the average number of blastocysts (about 3.2) appears to be greater than the estimated average litter size at birth (about 2.8) (Cresswell et al. 1992; Page et al. 1994; Neal and Cheeseman 1996), the relative importance of winter/spring matings and summer/autumn matings needs further investigation, although these figures suggest that if there is a reproductive advantage of later matings, it is less than that in American mink. Furthermore, there is no convincing evidence to reject the possibility that female badgers ovulate more than once within each of the two recognized mating seasons. These factors raise questions concerning the reproductive tactics of male badgers, as well as offering possible explanations as to why a consensus has proved elusive regarding the territorial and reproductive tactics of male badgers. Males may attempt to mate guard females only when they are receptive and only from unrelated males. As field observations of mating tend to be at the sett where potentially closely-related males reside, this might explain why little male aggression has been observed when females mate with multiple males. When there are no estrous females in a social group, males may increase their reproductive fitness by attempting to mate with receptive females from neighboring groups instead of guarding their own territory and the nonreceptive females within it.

The foregoing arguments, along with those in previous sections, suggest that good evidence for blastocyst turnover/mortality during embryonic diapause in the female is essential for understanding the evolution of the reproductive tactics of the male. Furthermore, we need to determine whether blastocyst turnover occurs within the mating season immediately after parturition, which is potentially the highest peak of reproductive activity in the European badger (e.g., Creswell et al. 1992). Unfortunately, hard evidence is currently lacking, and the necessary analytical resolution may not be achieved by postmortem analysis that is limited by the availability of carcasses. In the American mink, significant turnover of blastocysts and occurrence of superfetation was documented on the basis of experiments using males of different coat color genotypes to mate single females at different times, and surgically marking the corpora lutea from the first of the two ovulations (Shackelford 1952). Confirmation of superfetation, and to a certain extent estimation of blastocyst turnover during embryonic diapause in females, could be assessed using similar controlled manipulations on captive badgers of known genotype. Genetic fingerprinting could then be employed using a large number of animals to compare several different treatments-for example, comparison between females mating only during the early part of the breeding season and those doing so throughout the breeding season. Once the general trends have been discovered, further experiments could be designed to answer more specific questions. However, confirmation of the rate of blastocyst turnover, especially during the early stages of 
pregnancy, may require surgical examination that raises animal welfare issues as well as potentially impairing the condition of the females.

The majority of females that ovulate in the later stage of embryonic diapause (e.g., late summer onward) may be less than three years old (Ahnlund 1980). However, few females under the age of three years breed (da Silva et al. 1994; Woodroffe and Macdonald 1995b), and those that do appear to have lower reproductive success than older females (Creswell et al. 1992). Also, males sustaining testicular activity later into the summer acquire more bite wounds by autumn than other males, and may even become anemic (Woodroffe and Macdonald 1995a), which suggests that there may be a physiological cost associated with extended breeding activity in male badgers. These factors may therefore influence the reproductive tactics of male badgers, and different tactics may exist depending on an animal's age, physical condition, and circumstances.

Although male "status" (e.g., dominant or subordinate) may be an important element associated with mating tactics, feeding experiments with wild European badgers found no compelling evidence for dominance hierarchies within social groups, suggesting that identifying the conventional "dominance" hierarchy in badgers (if indeed there is one) is difficult (Macdonald et al. 2002b). Male badgers may be classified into "high" or "low" status (Stewart et al. 1999), but this is on the basis of body weight, age, and copulating frequency based on observations of individually identified male badgers around setts. Detailed observations of whether males differ in their mating efforts throughout the year, in relation to their physical and social status, are required to improve our understanding of male reproductive tactics in the European badger. As conventional field observations may not provide the appropriate resolution (e.g., temporal resolution and individual identification) to answer these questions, explorations of new types of observation techniques should be encouraged, such as continuous video surveillance (Stewart et al. 1997) and individual identification by noninvasive fur clipping (Stewart and Macdonald 1997).
The foregoing arguments shed light on the reproductive tactics of the male European badger at the time of analysis. The evolution of a reproductive tactic may not necessarily lead the process to a terminus, however, and the tug-of-war may continue both intra- and intersexually. For example, in the European badger, the $n$th stage of selection may favor those males that compete aggressively for mating opportunities during the postpartum mating period, and yet, the $(n+1)$ th stage of selection may favor those males that compete aggressively for mating opportunities all year round. Therefore, unless we have a fairly good idea of the evolutionary stage/history of a species, we may easily be lured into suggesting another just-so story.

The phylogenetic norm of the social system in badgers (consisting of eight species) appears to be solitary, and the European badger itself is unlikely to have evolved under circumstances where group living is the norm (Macdonald 2001). Thus, it is not clear whether the European badger has fully adapted to the high-density group-living society commonly found in the U.K. For example, the general lack of cooperative behaviors among group members (da Silva et al. 1994; Woodroffe and Macdonald 2000; Macdonald et al. 2002b) may simply suggest that the European badger has not evolutionarily adapted to such a society yet. Most behavioral observations of the European badger have been carried out in the U.K. Unless relevant observations become available from areas where badgers do not live in groups, it is difficult for researchers to truly tackle the evolution of reproductive strategies in the European badger.

\section{IMPLICATIONS FOR THE REPRODUCTIVE Tactics of Females}

Several advantages to females mating with multiple males have been suggested in terms of female reproductive fitness, including direct benefits such as fertilization assurance, mate retention, obtaining material benefits, avoiding male harassment, and devaluing a previous male's sperm, and genetic benefits such as promoting sperm competition, obtaining "good genes," increasing the genetic diversity of the litter, and avoiding genetic in- 
compatibilities (Stockley et al. 1994; Reynolds 1996; Jennions 1997; Arnqvist and Nilsson 2000; Jennions and Petrie 2000; Johnson 2001; Chapman et al. 2003; Wolff and Macdonald 2004). A female may achieve polyandry more successfully by prolonging the window of opportunity for mating, both to increase access to more males and to diminish the chance of any one male securing a monopoly. Without doubt, a female's window of opportunity is greatly extended by superfetation. In terms of fertilization assurance, considering the possible gradual death of blastocysts during the embryonic diapause, a female badger capable of superfetation would clearly be at an advantage.

Stewart et al. (1999) report that individuals of both sexes with a high sett fidelity perform more digging and collect more bedding than do transients and badgers of low site fidelity. Additionally, males of "high" status (large, mature, frequently copulating individuals) are more likely to dig than males of "low" status, notwithstanding the difficulty of identifying status in badgers (Macdonald et al. 2002b). Stewart et al. (1999) hypothesize that while highly resident adult females benefit from extending the sett to avoid direct reproductive competition among females, males of "high" status and site fidelity might extend the sett to encourage receptive breeding females into their group and/or to improve survivorship of sired litters. This suggests that resident females benefit from the labor provided by resident males, which they might not receive if they did not mate with them. The possibility of infanticide by other breeding females sharing the same sett (Cresswell et al. 1992) may lead to intense competition within a group for breeding space (Woodroffe et al. 1995; Macdonald et al. 2002a; DomingoRoura et al. 2003). This is reinforced by the observation that when an entire social group was removed, initial recolonization was almost exclusively by females (Tuyttens et al. 2000). Therefore, from a resident male's point of view, it would be desirable to eliminate cubs sired by male outsiders to improve the survival of their own cubs; however, multiple mating may disguise the true paternity of cubs (Wolff and Macdonald 2004). This is advantageous for females as it potentially re- duces the risk of infanticide from resident males. The foregoing argument suggests that multiple matings and superfetation benefit female reproductive fitness. Endocrinological studies suggest that embryonic diapause is probably a prerequisite for superfetation resulting in a single litter (such as that seen in the American mink and the European badger). As discussed above, following the initial fertilization, the corpora lutea of badgers do not initially produce sufficient progesterone to induce implantation, and this enables later estruses and ovulations (Canivenc and Bonnin 1981; Sundqvist et al. 1988; Mead 1993; Renfree and Shaw 2000). This embryonic diapause is terminated by the reactivation of corpora lutea that secrete progesterone, which is stimulated by the pituitary secretion (Canivenc and Bonnin 1981; Sundqvist et al. 1988; Mead 1993; Renfree and Shaw 2000). From this stage onwards, female badgers do not ovulate as the blastocysts are implanted and postimplantation pregnancy begins (Sundqvist et al. 1988; Mead 1993; Renfree and Shaw 2000). Therefore, without embryonic diapause, superfetation cannot occur while there is only one parturition.

Currently, mainstream adaptive hypotheses for the evolution of embryonic diapause deal principally with how it fine tunes mating and parturition times, and not with the origin of embryonic diapause (Kim King and Roger Powell personal communication). However, the foregoing arguments suggest that embryonic diapause, associated with superfetation, benefits females in the context of sexual conflict over reproduction, whether or not its function is to tune mating and parturition times. This may be the case if a female bears more than one offspring per litter, as seen in the Mustelidae. The existence of sexual conflict over reproduction may lead to the establishment of embryonic diapause in association with superfetation, and longer delays may have evolved thereafter. Obligate embryonic diapause is invariably found in species that breed annually at the most (Sandell 1990). The stoat Mustela erminea breeds once a year and exhibits embryonic diapause, whereas the ecologically and phylogenetically similar weasel $M$. nivalis usually breeds twice 
a year and does not possess embryonic diapause (Sandell 1990; Mead 1993). The combination of embryonic diapause and superfetation may therefore benefit females, regardless of their social system, by enabling cryptic polyandry. If a female has a small litter size, however, the potential benefits of the combination of embryonic diapause and superfetation may need further evaluation.

All species of the Phocidae and the Otaridae, whose reproductive biology is known, possess embryonic diapause (Lindenfors et al. 2003). They have a typical litter size of one, however, so they may not benefit from superfetation as much as the Ursidae (typical litter size of 1 to 3 ) and the Mustelidae (2 to 10 ). Unfortunately, knowledge on the combination of embryonic diapause and superfetation is limited, so an analysis of the life-history parameters that favor this combination is not possible. The occurrence of embryonic diapause in combination with superfetation is clearly testable though, and if this combination does occur broadly across other species, their sociobiology may require re-evaluation (Yamaguchi et al. 2004).

Previous studies have tried to explain the emergence of embryonic diapauses based on adaptive hypotheses (Sandell 1990; Mead 1993). However, recently, it has been suggested that there is one basal origin of embryonic diapause in the Carnivora phylogenetic tree at the point where the Canidae splits from the rest of the caniforms (doglike families; Lindenfors et al. 2003). This suggests that: (1) phylogenetic influence may be as strong as natural history parameters; and (2) the question should be why some species have lost it rather than developed it (Lindenfors et al. 2003). The phylogenetic effect clearly explains why no feliforms (catlike families) or Canidae possess embryonic diapause, whereas most of the caniform species (whose reproductive information is known) do possess it, regardless of their natural history parameters. For example, five of the six phylogenetic groups of the caniforms (except the Canidae) are invariable in terms of embryonic diapause within the family: Ursidae, Phocidae, Otaridae (including the walrus Odobenus rosmarus), and red panda Ailurus fulgens all have embryonic diapause, whereas the Procyonidae do not (Sandell 1990; Mead 1993; Renfree and Shaw 2000; Lindenfors et al. 2003). The only exception is the Mustelidae (including the closely-related Mephitidae), where considerable intrafamily variation exists (Sandell 1990; Mead 1993; Renfree and Shaw 2000; Lindenfors et al. 2003). This probable monophyletic origin of embryonic diapause in the Carnivora and the invariability of it in the other families suggest that the Mustelidae is the only group in which adaptive hypotheses of embryonic diapause can be tested (Lindenfors et al. 2003). Detailed research into the reproductive physiology (especially the occurrence of superfetation) of Mustelidae species, along with ecological studies, would enhance our understanding of why some species have lost (or regained) embryonic diapause, making the Mustelidae a good model taxon for studying sexual conflict in the reproduction of eutherian mammals.

Interdisciplinary research should be encouraged by combining detailed behavioral observations and genetic or surgical investigations into the occurrence of superfetation and blastocyst turnover during embryonic diapause in the Mustelidae, such as manipulative mating experiments using captive animals under controlled conditions. Once hard evidence has been collected in terms of embryonic diapause, research may be extended to other forms of reproductive delay, such as delayed fertilization and delayed development. This would give biologists greater insight into the evolution of delay in mammalian reproduction from both the natural and sexual selections' perspectives. As the Chiroptera achieve reproductive delay through all three of these mechanisms (Bernard and Cumming 1997; Renfree and Shaw 2000), captive bat breeding facilities suitable for mating manipulation experiments may benefit the study of the evolutionary biology of mammalian reproductive tactics.

ACKNOWLEDGMENTS

We thank Rodney Mead, Jerry Wolff, Mike Thom, Katrina Service, Christina Buesching, Chris Newman, and Daniel Dykhuizen for useful comments on this manuscript. 


\section{REFERENCES}

Ahnlund H. 1980. Sexual maturity and breeding season of the badger, Meles meles in Sweden. Journal of Zoology 190:77-95.

Amstislavsky S, Ternovskaya Y. 2000. Reproduction in mustelids. Animal Reproduction Science 60:571-581.

Arnqvist G, Nilsson T. 2000. The evolution of polyandry: multiple mating and female fitness in insects. Animal Behaviour 60:145-164.

Ben-David M. 1998. Delayed implantation in the marbled polecat, Vormela peregusna syriaca (Carnivora, Mustelidae): evidence from mating, parturition, and post-natal growth. Mammalia 62:269-283.

Bernard R T F, Cumming G S. 1997. African bats: evolution of reproductive patterns and delays. Quarterly Review of Biology 72:253-274.

Brotherton P N M, Manser M B. 1997. Female dispersion and the evolution of monogamy in the dikdik. Animal Behaviour 54:1413-1424.

Buesching C D, Newman C, Macdonald D W. 2002. Variations in colour and volume of the subcaudal gland secretion of badgers (Meles meles) in relation to sex, season and individual-specific parameters. Mammalian Biology 67:147-156.

Buesching C D, Stopka P, Macdonald D W. 2003. The social function of allo-marking in the European badger (Meles meles). Behaviour 140:965-980.

Caillol M, Mondain-Monval M, Rossano B. 1991. Gonadotrophins and sex steroids during pregnancy and natural superfoetation in captive brown hares (Lepus europaeus). Journal of Reproduction and Fertility 92:299-306.

Canivenc R. 1966. A study of progestation in the European badger (Meles meles L.). Pages 15-26 in Symposia of the Zoological Society of London Number 15: Comparative Biology of Reproduction in Mammals, edited by I W Rowlands. London: Academic Press.

Canivenc R, Bonnin M. 1981. Environmental control of delayed implantation in the European badger (Meles meles). Journal of Reproduction and Fertility Supplement 29:25-33.

Canivenc R, Bonnin-Laffargue M. 1963. Inventory of problems raised by the delayed ova implantation in the European badger (Meles meles L.). Pages 115128 in Delayed Implantation, edited by A C Enders. Chicago (IL): University of Chicago Press.

Chapman T, Arnqvist G, Bangham J, Rowe L. 2003. Sexual conflict. Trends in Ecology and Evolution 18:41-47.

Christian S F. 1995. Observations of extra-group mating and mate-defence behaviour in badgers, Meles meles. Journal of Zoology 237:668-670.

Cresswell W J, Harris S, Cheeseman C L, Mallinson P J. 1992. To breed or not to breed: an analysis of the social and density-dependent constraints on the fecundity of female badgers (Meles meles). Phil- osophical Transactions of the Royal Society of London B 338:393-407.

da Silva J, Macdonald D W, Evans P G H. 1994. Net costs of group living in a solitary forager, the Eurasian badger (Meles meles). Behavioural Ecology 5:151-158.

Domingo-Roura X, Macdonald D W, Roy M S, Marmi J, Terradas J, Woodroffe R, Burke T, Wayne R K. 2003. Confirmation of low genetic diversity and multiple breeding females in a social group of Eurasian badgers from microsatellite and field data. Molecular Ecology 12:533-539.

Dugdale H L, Macdonald D W, Newman C. 2003. Offspring sex ratio variation in the European badger, Meles meles. Ecology 84:40-45.

Dunstone N. 1993. The Mink. London: T. \& A.D. Poyser.

Fischer H E. 1931. Die Entwicklungsgeschichte des Daehses und die Frage der Zwillingsbildung. Verhandlungen der Anatomischen Gesellschaft 40:22-34.

Fries S. 1880. Über die Fortpflanzung von Meles taxus. Zoologischer Anzeiger 3:486-492.

Gouat J. 1985. Notes sur la reproduction de Ctenodactylus gundi rongeur Ctenodactylidae. Zeitschrift für Säugetierkunde 50:285-293.

Hall W H. 1987. Bovine superfetation by natural conception secondary to an embryo transfer pregnancy. Cornell Veterinarian 77:282-283.

Harrison R J, Neal E G. 1956. Ovulation during delayed implantation and other reproductive phenomena in the badger (Meles meles L.). Nature 177:977-979.

Hosken D J, Stockley P. 2004. Sexual selection and genital evolution. Trends in Ecology and Evolution 19:87-93.

Jennions M D. 1997. Female promiscuity and genetic incompatibility. Trends in Ecology and Evolution 12:251-253.

Jennions M D, Petrie M. 2000. Why do females mate multiply? A review of the genetic benefits. Biological Reviews 75:21-64.

Johnson D D P. 2001. Models of coexistence, conflict and cooperation. $\mathrm{PhD}$ thesis, University of Oxford.

Johnson D D P, Jetz W, Macdonald D W. 2002. Environmental correlates of badger social spacing across Europe. Journal of Biogeography 29:411-425.

Lindenfors P, Dalèn L, Angerbjörn A. 2003. The monophyletic origin of delayed implantation in carnivores and its implications. Evolution 57:19521956.

Macdonald D W. 1983. The ecology of carnivore social behaviour. Nature 301:379-384.

Macdonald D W. 2001. The New Encyclopedia of Mammals. Oxford: Oxford University Press.

Macdonald D W, Harmsen B J, Johnson P J, Newman 
C. 2004. Increasing frequency of bite wounds with increasing population density in Eurasian badgers, Meles meles. Animal Behaviour 67:745-751.

Macdonald D W, Newman C. 2002. Population dynamics of badgers (Meles meles) in Oxfordshire, U.K.: numbers, density and cohort life histories, and a possible role of climate change in population growth. Journal of Zoology 256:121-138.

Macdonald D W, Newman C, Stewart P D, DomingoRoura X, Johnson P J. 2002a. Density-dependent regulation of body mass and condition in badgers (Meles meles) from Wytham Woods. Ecology 83:20562061.

Macdonald D W, Stewart P D, Johnson P J, Porkert J, Buesching C. 2002b. No evidence of social hierarchy amongst feeding badgers, Meles meles. Ethology 108:613-628

Martin O Y, Hosken D J, Ward P I. 2004. Post-copulatory sexual selection and female fitness in Scathophaga stercoraria. Proceedings of the Royal Society of London B 271:353-359.

Maynard Smith J. 1978. The Evolution of Sex. Cambridge: Cambridge University Press.

Mead R A. 1968. Reproduction in eastern forms of the Spotted skunk (genus Spilogale). Journal of Zoology 156:119-136.

Mead R A. 1981. Delayed implantation in mustelids, with special emphasis on the spotted skunk. Journal of Reproduction and Fertility Supplement 29:11-24.

Mead R A. 1993. Embryonic diapause in vertebrates. Journal of Experimental Zoology 266:629-641.

Mead R A. 1994. Reproduction in Martes. Pages 404422 in Martens, Sables, and Fishers Biology and Conservation, edited by S W Buskirk et al. Ithaca: Cornell University Press.

Mondain-Monval M, Bonnin M, Canivenc R, Scholler R. 1980. Plasma estrogen levels during delayed implantation in the European badger (Meles meles L.). General and Comparative Endocrinology 41:143-149.

Montrose V T, Harris W E, Moore P J. 2004. Sexual conflict and cooperation under naturally occurring male enforced monogamy. Journal of Evolution ary Biology 17:443-452.

Neal E G, Cheeseman C. 1996. Badgers. London: T. \& A. D. Poyser Natural History.

Neal E G, Harrison R J. 1958. Reproduction in the European badger (Meles meles L.). Transactions of the Zoological Society of London 29:67-131.

Newman C, Macdonald D W, Anwar M A. 2001. Coccidiosis in the European badger, Meles meles in $\mathrm{Wy}$ tham Woods: infection and consequences for growth and survival. Parasitology 123:133-142.

Page R J C, Ross J, Langton S D. 1994. Seasonality of reproduction in the European badger Meles meles in south-west England. Journal of Zoology 233:69-91.

Poduschka W. 1996. Hyperthelie, Wurfgröße und Trächtigkeitsdauer bei der Unterfamilie Tenreci- nae Cabrera, 1925 (Mammalia: Insectivora: Tenrecidae), nebst Bemerkungen zur Längsstreifung der Gattung Hemicentetes. Contributions to Zoology 66:119-128.

Renfree M B, Shaw G. 2000. Diapause. Annual Review of Physiology 62:353-375.

Revilla E, Palomares F. 1999. Changes in the behaviour of a male Eurasian badger: evidence in favour of the anti-kleptogamy hypothesis? Acta Theriologica 44:471-476.

Revilla E, Palomares F. 2002. Spatial organization, group living and ecological correlates in low-density populations of Eurasian badgers, Meles meles. Journal of Animal Ecology 71:497-512.

Reynolds J D. 1996. Animal breeding systems. Trends in Ecology and Evolution 11:68-72.

Rogers L M, Forrester G J, Wilson G J, Yarnell R W, Cheeseman C L. 2003. The role of setts in badger (Meles meles) group size, breeding success and status of TB (Mycobacterium bovis). Journal of Zoology 260:209-215

Roper T J, Conradt L, Butler J, Christian S E, Ostler J, Schmid T K. 1993. Territorial marking with faeces in badgers (Meles meles): a comparison of boundary and hinterland latrine use. Behaviour 127:289-307.

Roper T J, Ostler J R, Schmid T K, Christian S F. 2001. Sett use in European badgers Meles meles. Behaviour 138:173-187.

Roper T J, Shepherdson D J, Davies J M. 1986. Scent marking with faeces and anal secretion in the European badger (Meles meles): seasonal and spatial characteristics of latrine use in relation to territoriality. Behaviour 97:94-117.

Rottenstein F. 1989. Superfetation in a pig. Magyar Allatorvosok Lapja 44:42-42.

Sandell M. 1989. The mating tactics and spacing patterns of solitary carnivores. Pages 164-182 in Carnivore Behaviour, Ecology, and Evolution, edited by J L Gittleman. London: Chapman and Hall.

Sandell M. 1990. The evolution of seasonal delayed implantation. Quarterly Review of Biology 65:23-42.

Schuyt G. 1981. Superfetation or spontaneous superfetation and double parturition in an ewe. Tijdschrift voor Diergeneeskunde 106:125-127.

Service K M, Harlow C M, Harris S. 2002. Occurrence of monthly oestrous in badgers (Meles meles): a mechanism for observed variation in breeding patterns? Advances in Ethology 37:149.

Shackelford R M. 1952. Superfetation in the ranch mink. American Naturalist 86:311-319.

Steck T, Bussen S. 1997. Conception during pregnancy (superfetation). Human Reproduction 12:1835-1836.

Stewart P D, Bonesi L, Macdonald D W. 1999. Individual differences in den maintenance effort in a communally dwelling mammal: the Eurasian badger. Animal Behaviour 57:153-161. 
Stewart P D, Ellwood S A, Macdonald D W. 1997. Remote video-surveillance of wildlife: an introduction from experience with the European badger Meles meles. Mammal Review 27:185-204.

Stewart P D, Macdonald D W. 1997. Age, sex, and condition as predictors of moult and the efficacy of a novel fur-clip technique for individual marking of the European badger (Meles meles). Journal of Zoology 241:543-550.

Stewart P D, Macdonald D W, Newman C, Cheeseman C L. 2001. Boundary faeces and matched advertisement in the European badger (Meles meles): a potential role in range exclusion. Journal of Zoology 255:191-198.

Stewart P D, Macdonald D W, Newman C, Tattersall F H. 2002. Behavioural mechanisms of information transmission and reception by badgers, Meles meles, at latrines. Animal Behaviour 63:999-1007.

Stockley P, Searle J B, Macdonald D W, Jones C S. 1994. Alternative reproductive tactics in male common shrews - relationships between mate-searching behavior, sperm production, and reproductive success as revealed by DNA-fingerprinting. Behavioral Ecology and Sociobiology 34:71-78.

Sundqvist C, Ellis L C, Bartke A. 1988. Reproductive endocrinology of the mink (Mustela vison). Endocrine Reviews 9:247-266.

Thom M D, Johnson D P D, Macdonald D W. 2004a. The evolution and maintenance of delayed implantation in the Mustelidae (Mammalia: Carnivora). Evolution 58:175-183.

Thom M D, Macdonald D W, Mason G J, Pedersen V, Johnson P J. 2004b. Female American mink, Mus tela vison mate multiply in a free-choice environment. Animal Behaviour 67:975-984.

Tuyttens F A M, Delahay R J, Macdonald D W, Cheeseman C L, Long B, Donnelly C A. 2000. Spatial perturbation caused by a badger (Meles meles) culling operation: implications for the function of territoriality and the control of bovine tuberculosis (Mycobacterium bovis). Journal of Animal Ecology 69:815-828.
Venge O. 1973. Reproduction in the mink. Royal Veterinary and Agricultural University, Copenhagen, Denmark, Yearbook 1973:95-146.

Wandeler A I, Graf M. 1982. Der Geschlechtszyklus weiblicher Dachse (Meles meles L.) in der Schweiz. Revue Suisse de Zoologie 89:1009-1016.

Weir B J. 1974. Reproductive characteristics of hystricomorph rodents. Symposium of the Zoological Society of London 34:265-301.

Whelan R, Hayden T J. 1993. The reproductive cycle of the female badger (Meles meles L.) in east Offaly. Pages 64-77 in The Badger, edited by T J Hayden. Dublin: Royal Irish Academy.

Wolff J O, Macdonald D W. 2004. Promiscuous females protect their offspring. Trends in Ecology and Evolution 19:127-134.

Woodroffe R. 1993. Alloparental behaviour in the European badger. Animal Behaviour 46:413-415.

Woodroffe R. 1995. Body condition affects implantation date in the European badger, Meles meles. Journal of Zoology 236:183-188.

Woodroffe R, Macdonald D W. 1995a. Costs of breeding status in the European badger, Meles meles. Journal of Zoology 235:237-245.

Woodroffe R, Macdonald D W. 1995b. Female/female competition in European badgers Meles meles: effects on breeding success. Journal of Animal Ecology 64:12-20.

Woodroffe R, Macdonald D W. 2000. Helpers provide no detectable benefits in the European badger (Meles meles). Journal of Zoology 250:113-119.

Woodroffe R, Macdonald D W, da Silva J. 1995. Dispersal and philopatry in the European badger, $M e$ les meles. Journal of Zoology 237:227-239.

Yamaguchi N, Sarno R J, Johnson W E, O'Brien S J, Macdonald D W. 2004. Multiple paternity and reproductive tactics of free-ranging American minks, Mustela vison. Journal of Mammalogy 85:432-439.

Zeh J A, Zeh D W. 2003. Toward a new sexual selection paradigm: polyandry, conflict and incompatibility. Ethology 109:929-950. 